\title{
Autos de denúncia da Cúria Metropolitana de São Paulo: análise do uso de sinais diacríticos na escrita de processos de feitiçaria
}

\author{
Helena de Oliveira Belleza Negro \\ Escola Técnica Getúlio Vargas (ETEC GV), São Paulo, São Paulo, Brasil \\ helena.oliveira@usp.br \\ http://orcid.org/0000-0001-5808-9368 \\ Marcelo Módolo \\ Universidade de São Paulo (USP), São Paulo, São Paulo, Brasil \\ modolo@usp.br \\ http://orcid.org/0000-0002-8633-7194
}

DOI: $\underline{\text { http://dx.doi.org/10.21165/el.v47i2.2110 }}$

\section{Resumo}

O presente artigo apresenta um dos manuscritos da coleção de autos de denúncia da Cúria Metropolitana de São Paulo. Dada sua importância histórica e linguística, abordaremos os principais pontos que se referem à descrição filológica do documento. Tendo em vista os diversos aspectos linguísticos presentes no manuscrito, será analisado o uso dos diacríticos agudo e do circunflexo, buscando-se atrelar à função que a ele é conferida pelos gramáticos da época a sua aplicabilidade.

Palavras-chave: filologia; linguística histórica; diacríticos.

Reports of denunciation of the Metropolitan Curia of São Paulo: analysis of the use of diacritical signs in the writing of witchcraft processes

\begin{abstract}
The purpose of this article is to describe and analyze one of the manuscripts of the collection of reports of denunciation of the Metropolitan Curia of São Paulo. Given its historical and linguistic importance, we will address the main points that refer to the philology description of the document. Considering the different linguistic aspects present in the manuscript, the use of the acute diacritic will be analyzed, trying to connect to the function that is given to it by the grammarians of the time and its applicability.
\end{abstract}

Keywords: philology; historical linguistics; diacritic signs.

\section{Introdução}

O documento ora analisado faz parte do conjunto de doze processos fotografados no Arquivo da Cúria Metropolitana de São Paulo, pertencentes a uma coleção destinada aos casos de feitiçaria no século XVIII, no território da então Diocese de São Paulo.

Para o presente trabalho, analisamos o processo de Tereza Leite e Escolástica Pinta da Silva, cujo estudo e edição semidiplomática estão sendo realizados por Pereira Porto (2017). 
Esse processo elaborado no ano de 1754 é composto pela denúncia de feitiçaria e pelos depoimentos contra Tereza e Escolástica, mãe e filha respectivamente, acusadas da morte de Manuel Garcia. Para além de uma contribuição para a compreensão de parte da história social dessa época, os documentos trazem particularidades da língua portuguesa que poderão ser localizadas apenas nos autos de denúncia, devido aos procedimentos de escrita adotados na elaboração desse tipo de documento.

A partir da edição semidiplomática já em curso por Pereira Porto (2017), identificamos o emprego de dois sinais diacríticos agudo e circunflexo, importantes para a identificação das características da língua da época.

\section{Considerações filológicas sobre o documento}

Conforme Spina (1977, p. 77) a filologia divide-se em três funções: função substantiva, adjetiva e transcendente, a saber:

$\left.1^{a}\right)$ Função substantiva, em que ela se concentra no texto para explicá-lo, restituí-lo à sua forma genuína e prepará-lo tecnicamente para publicação. 2a) Função adjetiva, em que ela deduz do texto aquilo que não está nele: a determinação de autoria, a biografia do autor, a datação do texto, a sua posição na produção literária do autor e da época, bem como a sua avaliação estética (valorização). $3^{\mathrm{a}}$ ) Função transcendente, em que o texto deixa de ser um fim em si mesmo da tarefa filológica, para se transformar num instrumento que permite ao filólogo reconstituir a vida espiritual de um povo ou de uma comunidade em determinada época.

O presente trabalho servir-se-á das três funções de maneira breve, com o objetivo de introduzir uma análise preliminar do documento escolhido para transcrição e estudo. O processo analisado é composto por trinta e sete fólios; dezesseis punhos distintos foram responsáveis pela escrita desse manuscrito. Dentre esses, seis já foram transcritos e será com base nessa transcrição semidiplomática já desenvolvida que as abordagens aqui presentes serão fundamentadas.

A tinta utilizada na escrita é clara, em tom avermelhado, possivelmente ferrogálica. A leitura também é dificultada pelo ataque das traças, que corroeram grande extensão de texto. Salienta-se que o material apresenta indícios de restauração, feita com papel arroz.

A escrita foi realizada em papel sem filigranas e sem pauta. Assim como os demais processos da Cúria, uma breve descrição sobre a natureza do auto foi apresentada em uma folha de papel almaço, pautada. As observações são realizadas por Jair Mongelli, então diretor do Arquivo, que assina o rodapé da folha, como apresentado na Figura 1. 


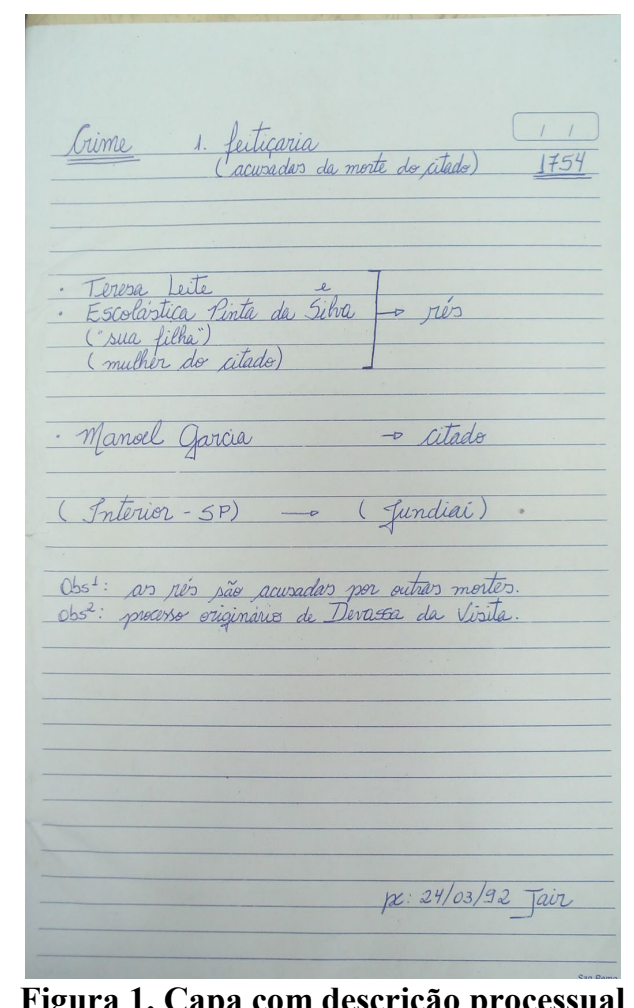

A guarda dos documentos é realizada em caixas confeccionadas em plástico polionda, identificadas por etiqueta externa, que menciona a série, período e localidade.

O manuscrito é composto pela denúncia de feitiçaria contra as rés, com depoimentos contrários e a favor das rés. Ao todo, 10 depoimentos foram transcritos até o momento, dentre os quais seis foram a favor de Escolástica e Tereza Leyte e quatro contra as mulheres.

Da abertura do processo aos depoimentos, os traçados ou punhos são distintos e as características de quatro escribas podem ser observadas no Quadro 1:

Quadro 1. Tipos caligráficos dos punhos

\begin{tabular}{|c|c|c|c|}
\hline Vocábulo & & Punho & Escriba \\
\hline & $<$ Escolastica $>$ & Punho 1 & Promotor Souza \\
\hline & & Punho 2 & $\begin{array}{l}\text { Salvador de Oliveira Preto - } \\
\text { Escrivão }\end{array}$ \\
\hline & $<$ Fscolastica $>$ & Punho 3 & $\begin{array}{l}\text { Fernando Pinto de Almeida - } \\
\text { Escrivão }\end{array}$ \\
\hline & $<$ Escolastica $>$ & Punho 4 & $\begin{array}{l}\text { Padre Bentho Joseph Leite - } \\
\text { Escrivão }\end{array}$ \\
\hline
\end{tabular}


O conteúdo documental é de extrema importância, pois, além de apresentar os procedimentos de acolhimento de acusação da época e dados histórico-sociais interessantes, mostram as características da escrita dos escribas da justiça eclesiástica.

Interessante seria saber o grau de instrução e origem de cada escriba para, então, traçar paralelo entre os usos gramaticais de cada indivíduo. Entretanto não dispomos dessa informação, mas essa relação será estabelecida com base nos dados documentais e históricos da época.

Apesar de tratar-se de um processo judicial, os escribas pertencem à justiça comum. Isso pode ser identificado pelos nomes apresentados no decorrer do processo, visto não apresentarem nenhuma titulação eclesiástica, ao firmarem assinatura. Soma-se a isso o fato de as Ordenações Filipinas também apresentarem procedimentos específicos e distintos para os processos inquisitoriais.

As abreviaturas foram pouco utilizadas, aparecendo nas seguintes ocasiões:

Quadro 2. Abreviaturas encontradas no manuscrito

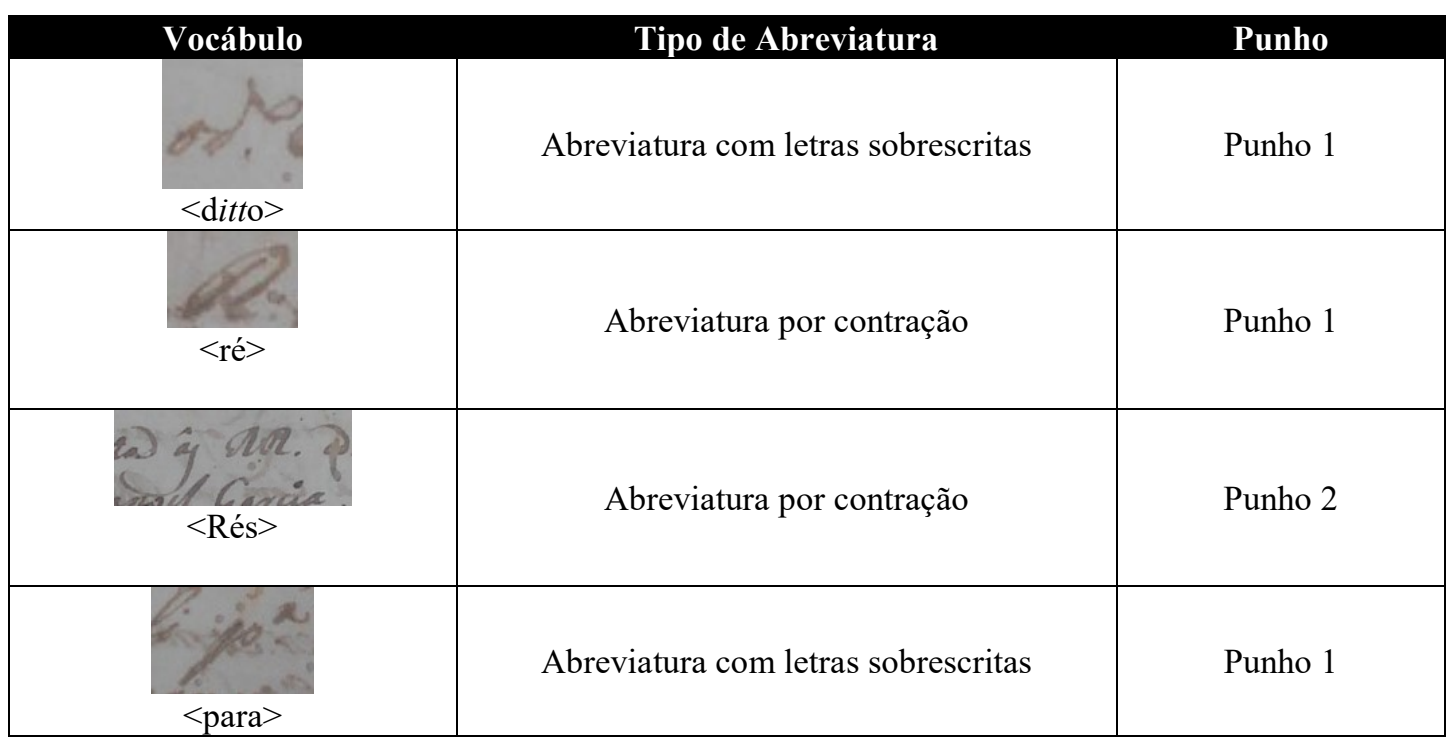

Os traçados e as abreviaturas apresentam as características da escrita dos diferentes punhos. As abreviaturas, recurso utilizado nos documentos antigos, foram desenvolvidas de acordo com as ocorrências presentes por extenso no documento. Para tanto, os critérios adotados na edição semidiplomática serão os balizadores para a transcrição.

Achados ortográficos também nos apresentam as características da escrita no XVIII, como o uso de $<\mathrm{h}>$ para apresentar a tonicidade vocálica em $<$ Jundiahy $>$; o $<\mathrm{y}>$ para representar a nasalidade em $<$ May $>$, o diacrítico circunflexo para representar a tonicidade e abertura vocálica em $\langle$ pê $>$; $<\mathrm{m}>$ em final de sílaba para representar a nasalidade no lugar de $<$ ão $>$ como em $<$ certam $>$, o uso de letras geminadas como em $<$ elle $>$ e $<$ ditto $>$ ou, ainda, os diferentes usos fonéticos como em $<$ falcidade $>$ e $<$ camisa $>$. 
Dentre os sinais diacríticos foram localizados o til em final de sílaba, com a finalidade de demonstrar a nasalidade, o circunflexo e o agudo para representar a tonicidade. Será com enfoque nas funções do agudo e do circunflexo que analisaremos as ocorrências destes diacríticos.

\section{Análise do uso de sinais diacríticos}

Dentre os diversos aspectos linguísticos já mencionados, optamos pela análise do uso dos sinais diacríticos, especificamente, os sinais que representam tonicidade - $o$ agudo e o circunflexo.

Optou-se pelos dois diacríticos devido à singularidade com que foram utilizados nos manuscritos. Não foram raras as ocorrências em que o agudo foi encontrado como marca de nasalidade. Estudos realizados em autos de devassa do século XVIII por Negro (2017) apresentam estes índices, que demonstram que 85\% das aparições do agudo tinha como função a representação da nasalidade.

A literatura ortográfica contemporânea à escrita do processo de Tereza e Escolástica faz referência ao uso destes sinais. Embora, em contexto diferente ao atualmente utilizado, estes sinais gráficos fossem aplicados para marcar a tonicidade silábica, com a função principal de demonstrar a diferença lexical.

No processo analisado foram encontradas as seguintes ocorrências:

Quadro 3. Vocábulos e diacríticos

\begin{tabular}{|c|c|c|c|}
\hline Ocorrência & Palavra/expressão & Diacrítico & Punho \\
\hline 1 & Pê & Circunflexo & Punho 1 \\
\hline 2 & Só & Agudo & Punho 1 \\
\hline 3 & â catorze (annos) & Circunflexo & Punho 2 \\
\hline 4 & â mais de (10 annos) & Circunflexo & Punho 2 \\
\hline 5 & Âs Res & Circunflexo & Punho 2 \\
\hline 6 & Cuyabâ & Circunflexo & Punho 2 \\
\hline
\end{tabular}

Os vocábulos e expressões estão presentes no texto como mencionado no Quadro 3. Identificamos que os diacríticos agudo e circunflexo são utilizados para a mesma função nas ocorrências 1, 2 e 6: representar a tonicidade silábica.

No entanto, as ocorrências 3 e $4-<$ â catorze $>$ e $<$ â mais de $>-$ apresentam o circunflexo com uma função verbal, neste caso, do verbo haver. Importante destacar que o uso do $<\mathrm{h}>$ para os ortógrafos setecentistas representava o uso latino de aspiração, como menciona Feijó (1743, p. 20), "para com os Latinos naõ he letra, mas hum sinal de aspiração nas letras, a que se ajunta”, ou, ainda, como aponta Leão (1576, p. 7): 
[...] não he letra, mais que na figura. Mas he hũa aspiração ou assopro. [...] porem ainda que pareça esta aspiração ociosa, pola não pronũciarmos, he porem necessária, para guardar a orthographia dos nomes Latinos, \& Gregos, para per ella se conhecer a origem, \& etymologia [...].

Diante disso, podemos supor que o uso do sinal gráfico nestas ocorrências tinha como objetivo substituir a consoante $<\mathrm{h}>$. Representando a aspiração ou substituindo $\mathrm{o}$ agudo em sílabas tônicas, como em $<$ he $>$, o $<\mathrm{h}>$ nos casos mencionados foi suprimido pelo circunflexo.

Interessante observar que tais aplicações foram realizadas por dois escribas distintos. O primeiro fez uso dos dois diacríticos (agudo e circunflexo), enquanto o segundo utilizou apenas o circunflexo, o que evidencia o condicionamento da escrita aos saberes dos tabeliães.

Já na ocorrência 5, o circunflexo é responsável pela contração de preposição e artigo, atribuição do diacrítico grave. Esse sinal gráfico, embora mencionado por alguns ortógrafos, dentre eles, Figueiredo (1722), Feijó (1734), Verney (1746) e Bacelar (1786), não era utilizado até o início do século XIX para representar as contrações de vogal e preposição. Para esse fim, usava-se o agudo. Há três situações em que a expressão ocorre e a inserção do diacrítico se dá em momentos distintos, comprovando que os escribas, punhos 1 e 2, fizeram uso do sinal gráfico para uma finalidade específica. Há, portanto, um regramento desse escriba que, seguramente, realiza-se mais no nível cognitivo, formalizando-se em sua percepção da língua escrita.

1 "e por/digo no que respeita âs Res disse ser subri/nho"

2 "não ser/verdade o que se imputava âs Res, e mais"

3 "que conhe/ceo sempre as Res, procederem bem"

$\mathrm{O}$ uso de um ou outro diacrítico pode apoiar-se na literatura pedagógica e especializada da época. Influenciados pelas mudanças apresentadas pelas políticas educacionais de Marquês de Pombal, iniciadas em meados do século XVIII, métodos educacionais e novas formas de ensino de leitura e escrita passaram a ser adotados. Como o documento analisado é dessa época, os escribas responsáveis pela elaboração do auto podem ter sido influenciados pelos conceitos de Verney (1746), cuja proposta no Verdadeiro método de estudar rompe com o modelo pedagógico apresentado pelos jesuítas.

Apesar da alternativa apresentada pela Nova escola para aprender a ler, escrever e contar (1722), livro de primeiras letras escrito por Manuel de Andrade Figueiredo, privilegiando o uso do agudo como método de sistematização didática, os escribas utilizaram o circunflexo para demarcar a contração e a tonicidade, o que pode ser atribuído ao contexto em que estavam inseridos e às convenções específicas atreladas aos documentos inquisitoriais.

Sob uma análise direcionada para o punho 1, que realiza o uso dos dois diacríticos, e partindo para o percurso histórico das palavras acentuadas, os vocábulos $<$ pê $>$ e $<$ só $>$ apontam para a queda da consoante intervocálica. 


\section{1. $\quad$ pedem $>$ peem $>$ pê \\ 2. $\quad$ soo $>$ solo $>$ ssoo $>$ só}

Sobre duplicidade vocálica e suas formas de representação, Verney (1746) defende a simplificação da escrita e a contração vocálica, adotando o uso do sinal diacrítico para delimitar a contração (pée, sóo). Assim como ele, outros ortógrafos que o antecederam sugeriram esse uso, como é o caso de Leão (1576).

O escriba também adotou o critério de uso do diacrítico para representar a contração das vogais iguais em uma mesma palavra (pê, só) e a contração de partículas com funções distintas (âs Res) remetendo a uma escrita clássica, em que alguns gramáticos orientavam a aplicação do circunflexo para os casos de contração plural, como é o caso. Gândavo faz referência a esse uso no capítulo Dos accentos qve se hão de vsar em algũas letras, ou vocabulos que teuerem duvidosa a significação, em que o ortógrafo faz referência ao uso do circunflexo, quando houvesse a junção do artigo e da preposição no plural. Como regra, ele defende:

Qvando este articulo a, ou as, se ajuntar a algũs nomes femeninos, a que se concede ou nega algũa cousa, terá hum accento em cima, aßicomo, à vossa geração se deue esta honra, ás cousas diuinas se ha de ter grande acatamento, \&c. Enfim que a $\beta i$ como dixeramos, ao, ou aos em nomes masculinos, a $\beta$ i diremos à, ou âs, com este accento em cima em nomes femininos: saluo quando se ajuntar a algũs nomes próprios [...]. (GÂNDAVO, 1574, p. 33)

Diante desses aspectos, identificamos que os usos aplicados aos diacríticos nos documentos eclesiásticos remetem à utilização que os gramáticos e ortógrafos quinhentistas realizavam, como Gândavo, por exemplo.

Em todo o corpus, identificam-se outras ocorrências em que a escrita pseudoetimológica é presente como em catholica, damno, Thereza, sanctos e elle.

Partindo disso, evidencia-se que os usos praticados pela Igreja buscam a cultura clássica, remetendo aos tradicionalismos e secularidade da instituição.

\section{As análises dos dados encontrados}

O Tribunal do Santo Ofício seguia Regimento próprio, atualizado em 1640, que atribuía as funções de cada representante e identificava essas atividades auxiliares na identificação da importância dos escribas e no modo com que eram elaborados os documentos. Para tanto, buscamos as atribuições dos cargos responsáveis pelas atividades do Tribunal e o documento descrevia o seguinte:

II. Haverá em cada Inquisição tres Deputados salariados, com voto decisivo, como sempre se costumou, e os mais sem salario, que parecer ao Inquisidor Geral, pessoas escolhidas, de letras, idade, virtude e consciencia, que bem possam servir ao diante o santo officio de Inquisidores - e assim um Promotor, tres Notarios, dous Procuradores, que defendam os presos, Meirinho, Alcaide do carcere, dous Solicitadores, ou mais, sendo necessário um Porteiro da Mesa do despacho, um Despenseio, e os Guardas necessários para serviço e ministerio do carcere - e tambem haverá Qualificadores, que revejam e examinem os livros, e censurem as proposições, nas Inquisições, que ordenar o Inquisidor Geral. 
Resgatar as atividades desses profissionais auxilia-nos a identificar a formação e, possivelmente, a influência dos escribas. Em todo o fac-símile, localizamos as funções previstas no Regimento, dentre elas, o comissário, juiz eclesiástico e o escrivão, por exemplo. Em um dos trechos retirados do auto de devassa, podemos identificar esses profissionais e confrontar o manuscrito com o regimento da época.

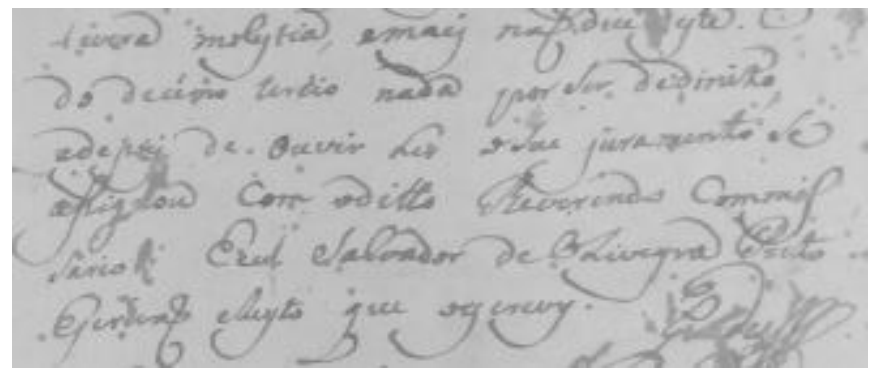

tivera moléstia, e mais naõ disse deste. E do decimo tertio nada por se dedireito edepois de ouvir Ler oSeu juramento se assignou com o ditto Reverendo commis sario Eeu Salvador deOliveyra Preto

Escrivã̃ eleyto que oescrevy.

O regimento estabelece as funções de cada representante do Tribunal e o escrivão é nomeado conforme a necessidade do comissário, como apresenta o Livro 1, título XI

1 Os Commissarios do Officio, além das qualidades, deq se faz e menção no tit. deste liuro, serão pessoas Ecclesiasticas, de prudência, \& virtude conhecida, \& achando-se letrados, serão preferidos aos mais, \& guardarão inteiramẽnte o que se dispõem nos parágrafos do mesmo titulo

5 Para escrever nas Diligencias, chamaraõ a pessoa, que nas comissões lhe for nomeada por Escriuão, \& não hindo nomeada, o Escrivão do seu cargo; \& não tendo Escriuaõ, nẽ o achando nomeado nas cõmissoẽs, escolheraõ hũa pessoa Ecclesiastica, a mais suficiente, q se achar, \& em cazo que se não ache com as qualidades, que se requere, tomaraõ hum familiar. Se as testemunhas nomeadas nas commissoens forem mortas, ou que ausentes, mandaraõ passar disso certidão pelo mesmo Escriuaõ no fim da diligencia, declarando onde os ausentes rezidem, declarando onde os ausentes rezidem, para que os Inquisidores fação o que mais conuier.

6 Se nas terras, em que viuerem acontecer algũa couza, que encontre a pureza da nossa Santa Fê, ou per alg ua outra via pertença ao santo Officio, auizaraõ por carta sua aos Inquisidores, paraque mandem prouer na matéria com o remédio, que conuem ao serviço de Des; \& hauendo temor dos culpados se ausentarem, ou sendo o negocio de muita importância, mãdaraô o auizo por hũ próprio, q eu os Inquisidores mãdaraô pagarseu caminho.

Verifica-se que o escrivão não é uma atividade determinada para um profissional específico e a escritura dos depoimentos poderia ser realizada por qualquer pessoa nomeada pelo comissário com a condição de ser "Pessoa Ecclesiastica, ou Secular a mais idonea, que achar, e que melhor saiba escrever". Diante disso, presume-se que o escriba, conhecedor da escrita, não precisaria necessariamente conhecer o assunto, pois 
apenas transcreveria os depoimentos, de acordo com as diretrizes transmitidas pelo comissário. A estrutura do documento de processos criminais eclesiásticos é abordada por Marquilhas (2003, p. 16), em A faculdade das letras:

Atrás da agilidade que os agentes inquisitoriais revelaram na manipulação do poder organizador da escrita estava uma forte tradição, iniciada na antiga Roma com a energia legisladora e administrativa da classe culta, herdada e cultivada, ao longo da Idade Média e no início da Idade Moderna, tanto pelos núcleos de poder eclesiástico como pelas chancelarias reais. É no direito romano que radica a componente organizativa dos registros papais, cujos documentos burocráticos repetem, logo desde o século V, modelos saídos da prática imperial; é para a mesma fonte que remete, no caso da Península Ibérica, a atividade legal e administrativa dos visigodos, continuada depois, a partir do século XII, nas chancelarias dos reinos cristãos.

Ao que parece a tradição mencionada por Marquilhas estende-se à escrita, pois as análises dos usos dos diacríticos apresentam a tonicidade como função do circunflexo e de crase do artigo com preposição. Em um percurso historiográfico, identificamos que tal aplicação era aconselhada por gramáticos seiscentistas, o que remete às aplicações humanistas do uso da linguagem.

Entre os séculos XVI e XVII, os gramáticos e ortógrafos portugueses buscavam manter as características latinas na escrita portuguesa ao passo que também procuravam encontrar uma identidade para o povo português, centralizando, então, no idioma essas buscas. Para tanto, o uso e a adoção de marcas e aspectos que solidificassem a língua portuguesa como meio alheio a outras intervenções, principalmente, espanholas, era a tônica das gramáticas.

\section{Considerações finais}

As tendências iluministas, como explana Carvalho (2007) ao estudar a influência do padroado e dos magistrados nos movimentos sociais do século XIX, não foram suficientes para sobrepujar o tradicionalismo da escrita e a influência do modelo secular na escrita eclesiástica do período.

Ainda que sua obra seja contemporânea em relação à escrita da devassa de Escolástica Pinta da Silva, aparentemente, os escribas buscavam conservar as práticas quinhentistas, visando buscar a tradicionalidade, tendo em vista que procura resgatar características humanistas na tradição escrita.

Como afirma Certeau (2011, p. 208),

[...] o recuo para a linguagem "escriturária". Inspira-se cada vez mais numa nostalgia das origens. O trabalho que leva a história do cristianismo às suas origens, graças à exegese, ou que se esforça por arrancar a moral da casuística probabilista e fundar um rigorismo "mais puro" sobre um retorno ao Evangelho. [...].

O uso do circunflexo demonstra um diferencial quanto ao conhecimento e aplicação da tonicidade na língua. No século XVI, o uso do circunflexo para representar a crase de artigo e preposição em ocorrências no plural, assim como as situações em que há necessidade de apontar a tonicidade vocálica como em $<$ pê $>$ e $<$ só $>$. Já no XVII seu uso foi difundido para demarcar as distinções lexicais por gramáticos como Vera 
(1631), que, inclusive, baseia sua Ortografia na obra de Duarte Nunes do Leão (1576) e Barreto (1681).

Dentre os apontamentos, os usos encontrados nos documentos assemelham-se aos usos da fase pseudoetimológica, presentes nas gramáticas quinhentistas e seiscentistas.

\section{REFERÊNCIAS}

BARRETO, J. F. Ortografia da língua portuguesa. Lisboa: Officina de Joam da Costa, 1683.

CARVALHO, J. M. de. A construção da ordem. Rio de Janeiro: Civilização Brasileira, 2007.

CERTEAU, M. A escrita na história. 3. ed. Rio de Janeiro: Forense, 2011.

Coleção Benedicto Ottoni. Lisboa: Officina de Miguel Manescal da Costa, 1764. Disponível em: <http://bdlb.bn.gov.br/acervo/handle/123456789/273990>. Acesso em: 30 jul. 2017.

BACELAR, B. L. M. Grammatica philosophica e orthographia racional da lingua portugueza, para se pronunciarem e escreverem com acerto os vocabulos d'este idioma. Lisboa: Off. de Simão Thaddeo Ferreira, 1783.

CUNHA, N. Regimento do Santo Officio da Inquisição dos reinos de Portugal. 1774.

FEIJÓ, J. de M. M. Orthographia ou arte de escrever e pronunciar com acerto a lingua portugueza para uso do Excellentissimo Duque de Lafoens. Lisboa: Na Officina de Miguel Rodrigues, $1734 . \quad$ Disponível em: $<$ http://purl.pt/index/geral/aut/PT/31910.html $>$. Acesso em: 25 set. 2016.

FIGUEIREDO, M. de A. Nova escola para aprender a ler, escrever, e contar oferecida a augusta majestade D. João V, rey de Portugal. Lisboa: Officina de Bernardo da Costa de Carvalho, 1722. Disponível em: <http://purl.pt/107>. Acesso em: 25 out. 2015.

LEÃO, D. N. do. Orthographia da lingoa portuguesa: obra vtil \& necessaria assi pera bem screuer a lingoa Hespanhol como a Latina \& quaesquer outras que da Latina teem origem. Lisboa, 1576. Disponível em: <http://purl.pt/index/geral/aut/PT/47390.html>. Acesso em: 20 mar. 2010.

MARQUILHAS, R. A faculdade das letras: leitura e escrita em Portugal no século XVII. Bragança Paulista: EDUSF, 2003.

NEGRO, H. de O. B. Usos e normas: estudo diacrônico sobre os usos dos diacríticos na língua portuguesa do Brasil. 2017. 380 f. Tese (Doutorado em Filologia e Língua Portuguesa) - Faculdade de Filosofia, Letras e Ciências Humanas, Universidade de São Paulo, São Paulo, 2017. Disponível em: $<$ http://www.teses.usp.br/teses/disponiveis/8/8142/tde-26062017-112626/>. Acesso em: 15 jul. 2018.

SPINA, S. Introdução à edótica (Crítica textual). São Paulo: Cultrix. 1977. 
PEREIRA PORTO, N. Feitiçaria paulista: transcrição e estudo de processo crime da justiça eclesiástica no Brasil do século XVIII. 2017. 148 f. Dissertação (Mestrado em Filologia e Língua Portuguesa) - Faculdade de Filosofia, Letras e Ciências Humanas. Universidade de São Paulo, São Paulo, 2017.

VERA, A. F. de. Orthographia ou modo para escrever certo a língua portuguesa. Lisboa: Mathias Rodriguez, 1631.

VERNEY, L. A. Verdadeiro método de estudar para ser útil à república e à igreja: proporcionado ao estilo, e necessidade de Portugal. Exposto em varias cartas, escritas poloto R. P. ***Barbadinho da Congregasam de Italia, ao R. P *** Doutor na Universidade de Coimbra. Valensa: Oficina de Antonio Balle. 1746. Disponível em: $<\underline{\text { http://purl.pt/118> }}$. Acesso em: 01 mai. 2016.

Recebido em: 19/04/2018

Aprovado em: 26/04/2018 